\title{
OS DIREITOS LINGUÍSTICOS NO ENSINO DE SURDOS NO BRASIL: UMA VALORIZAÇÃO DE LÍNGUAS?
}

\author{
Verônica de Oliveira Louro Rodrigues
}

RESUMO

Este trabalho trata do ensino de surdos no Brasil, em relação a seus direitos linguísticos de valorização da Língua Brasileira de Sinais (Libras) e da Língua Portuguesa dentro do Instituto Nacional de Educação de Surdos (INES), comparando o Plano de Desenvolvimento Institucional com a Declaração Universal de Direitos Linguísticos de 1996 e com as principais políticas públicas do país voltadas para esse grupo minoritário.

PALAVRAS-CHAVE: direitos linguísticos; surdos; língua

“[...] A minoria é um lugar de transformação e passagem, onde se animam os fluxos de transformação de uma identidade ou de uma relação de poder" (ORLANDI, 2014, p. 32)

\section{Introdução}

ste trabalho traz à tona um tema de muita importância: o ensino de surdos da educação básica no Brasil e, em específico, dentro do Instituto Nacional de Educação de Surdos (INES) no Rio de Janeiro. Trata-se de comparar um dos documentos institucionais dessa instituição, conhecido como Plano de Desenvolvimento Institucional (PDI-INES), com a Declaração Universal de Direitos Linguísticos de 1996, assinada em Barcelona de 6 a 9 de junho de 1996, e as principais políticas públicas do país voltadas para esse grupo minoritário, tais quais a Lei no 10436 de 24 de abril de 2002, o 
Decreto no 5626 de 22 de dezembro de 2005 e o Decreto no 7.387, de 9 de dezembro de 2010.

Objetiva-se, com essa comparação, fazer uma avaliação de políticas linguísticas sob os preceitos de Cooper (1997), Calvet (2002) e Severo (2013) no ensino para surdos da educação básica, em relação a seus direitos linguísticos de valorização da Língua Brasileira de Sinais (Libras) - língua minoritária e primeira língua (L1) - e da Língua Portuguesa - língua majoritária e segunda língua (L2).

Justifica-se a escolha desses protagonistas, porque ingressei no Instituto Nacional de Educação de Surdos (INES) para dar aula de português e literatura na Educação Básica em 2010. Até esse momento, nunca havia convivido com surdos, nas minhas esferas sociais anteriores, nem havia refletido sobre o processo de ensino-aprendizagem desse sujeito enquanto aluno.Chegando ao instituto sentia um misto de alegria e ansiedade, pois tinha muito a aprender em relação à surdez ${ }^{1}$ e me deparei com o enorme desafio de ensinar uma língua com a qual muitos dos meus alunos náo se identificam por meio de uma segunda língua (L2) que eu não dominava. Com o passar do tempo, fui ganhando mais confiança com a Libras, minha L2, além do espanhol, mas muito me preocupava com o modo de ministrar aulas de português como L2, na sua modalidade escrita. Meus alunos são, em sua grande maioria, do Ensino Médio (EM) noturno, ou seja, muitos jovens e adultos que enxergam na sua formação uma possiblidade de melhorar suas condiçóes de trabalho e de vida. No meu exercício de profissáo, dedico-me a ensiná-los a ler e escrever em português, o que pode gerar uma série de questionamentos que me interessaria pesquisar para aprimorar o processo de ensino-aprendizagem em sala de aula. Com o tempo, observo que os alunos encaram as línguas de modo diferente: o português é sempre uma língua quase inalcançável, enquanto a Libras, aquela que os deixa confortáveis para expressão de sentimentos e ideias. Com isso, no momento, cabe investigar como as políticas linguísticas do Brasil têm-se dedicado a garantir os direitos linguísticos, de valorização da Libras e da Língua Portuguesa, para os surdos da educação básica.

1 Todos os servidores que tomaram posse no instituto, em dezembro de 2009, tiveram um curso de capacitação de um mês, para aprender Libras pela manhã, e outro curso, de tarde, voltado para refletir sobre as especificidades do surdo em diferentes esferas sociais. 


\section{Contextualização}

Escolhe-se o Instituto Nacional de Educação de Surdos (INES) como palco da pesquisa, porque, além de ser o lugar onde trabalho, reconhecido como um órgão específico, singular e integrante da estrutura organizacional do Ministério da Educação (MEC) - conforme Decreto no 7.690, de 2012, vigente no momento - apresenta uma historicidade simbólica: primeira escola para surdos do Brasil, criada ainda no período imperial. Ademais, é a única escola na cidade do Rio de Janeiro que só atende alunos surdos e se caracteriza por oferecer uma educação bilíngue, cuja orientação é de que a língua de instrução e de comunicação seja a Libras em todos os espaços.

Embora o PDI-INES - com atuação prevista de 2012 a 2016 - tenha sido elaborado para atender principalmente às demandas do Departamento de Ensino Superior do INES (DESU), foram analisados os objetivos e metas no que se refere às políticas públicas e relaçōes institucionais, mas também à educação básica: o colégio de aplicação (CAp-INES). Esses trechos foram comparados a documentos legais que instituem, regulamentam e estabelecem parâmetros para valorização e promoção da Libras (Lei 10436/02 e Decreto 5626/05), além disso já completaram mais de dez anos de existência, portanto, destaca-se um momento propício para uma avaliaçáo de políticas linguísticas. Outros textos legais foram selecionados por tratar dos direitos linguísticos e fortalecimento das línguas minoritárias: a Declaração Universal dos Direitos Linguísticos de 1996 e o Decreto 7.387 de 2010.

\section{Uma Breve Trajetória sobre a Política Linguística}

O surgimento do campo de estudo das Políticas Linguísticas tanto na Europa como nos Estados Unidos (EUA) se deu com o advento da Sociolinguística. Constituíram-se como uma disciplina, a partir da segunda metade do século XX, e se consolidaram nos finais da década de 50 e nos anos 60 . A Política Linguistica e o Planejamento Linguistico se relacionam por áreas de pesquisa e interesse.

Segundo Severo (2013), a primeira área tem se voltado para uma prática de caráter estatal-linguístico, enfocando o trabalho sobre a "oficialização de línguas, a escolha de alfabeto para a representação gráfica de uma língua, a 
hierarquização formal das línguas (línguas de trabalho, oficiais, nacionais, por exemplo) ” (p. 451). Já a segunda dá destaque à realização das decisões sobre a língua através de "estratégias (políticas), como as políticas educacionais, com vistas a influenciar o comportamento dos sujeitos em relação à aquisição e uso dos códigos linguísticos" (COOPER, 1989 apud SEVERO, 2013, p. 452).

$\mathrm{O}$ autor pioneiro que desenvolveu esse conceito de planejamento linguistico foi Haugen (1961) que passou a trabalhar com as noçóes de status e corpus, diferenciando a forma da língua (planificação linguística) da função linguística (cultura da língua como, por exemplo, oficial, nacional, escolar etc.). Dessa forma, política linguística passou a ser delimitada como as grandes escolhas referentes às relações entre as línguas e determinadas sociedades, enquanto a planificação linguística é a política linguística colocada em prática, simbolizando uma ação de autoridade (LAGARES; SAVEDRA, 2013).

Calvet (2002) embasado em Haugen (1966) trouxe grandes contribuiçóes ao observar o contato entre comunidades linguísticas diferentes. No campo do planejamento linguístico, quando uma ação planejada sobre a língua não é satisfatória, busca-se uma segunda situação que se deseja alcançar, por isso se observam determinadas funçóes sociais como a escrita, o léxico, a padronização, a neologia e a "prática social, em resposta às necessidades sociais, que desempenhou o papel motor” (CALVET, 2007, p. 68). As intervençôes, surgidas por meio da interação entre as comunidades linguísticas, caracterizam-se por in vivo, resultado das práticas sociais, e in vitro, relativo ao poder do Estado e dos pesquisadores, sem levar em conta os anseios e necessidades das comunidades em questão. Essa dicotomia constitui, portanto, as bases para o planejamento linguístico.

No caso da minoria linguística de surdos no Brasil, a primeira intervenção procede das práticas sociais como, por exemplo, a mobilização de surdos para reconhecimento de sua língua e as diferenças de sinais para designar um objeto. A segunda leva em consideração a opinião e estudos de pesquisadores, linguistas, mas, principalmente, de quem detém o poder, o Estado.

A Libras já sofreu uma intervenção política, no caso, um planejamento de status ou uma intervenção "in vitro" (CALVET, 2007, p 29, 68), que diz respeito à intervenção sobre o reconhecimento e a função social da língua: "É reconhecida como meio legal de comunicação e expressão, Língua Brasileira de Sinais - Libras (...) Libras não poderá substituir a modalidade escrita da língua portuguesa”. (BRASIL, Lei 10436/02, art. 1º) 
Como a Libras não tem um sistema de escrita consolidado entre os seus usuários, a língua portuguesa assume esse papel oficialmente de registro escrito para os surdos. Essa lei tem muito a contribuir para o papel da língua portuguesa no ensino para os surdos, já que não se torna mais necessário ensinar ao surdo a oralização na escola, para que aconteça a comunicação com os ouvintes, por isso as modalidades a serem privilegiadas devem ser a leitura e a escrita do português. Além disso, observa-se uma valorização da Libras, mas não em detrimento da Língua Portuguesa, ou seja, elas devem coexistir em modalidades diferentes. A língua majoritária não pode ser substituída nem equiparada à língua minoritária, portanto constata-se que a primeira detém um poder que a segunda não possui.

Destacamos ainda o Decreto 5626/05 que regulamenta a Lei 10.436 de 2002 e artigo 18 da Lei 10.098 de 2000, asseverando sobre a inclusão da Libras como disciplina curricular; a formação do professor de Libras e do instrutor de Libras; o uso e a difusão da Libras e da Língua Portuguesa para o acesso das pessoas surdas à educação; a formação do tradutor e intérprete de Libras - Língua Portuguesa; a garantia do direito à educação das pessoas surdas ou com deficiência auditiva; a garantia do direito à saúde das pessoas surdas ou com deficiência auditiva; o papel do poder público e das empresas que detêm concessão ou permissão de serviços públicos, no apoio ao uso e difusão da Libras.

Notamos que o conceito de politica linguistica é complexo. Para o pesquisador Noss (1971 apud SEVERO, 2013), a intervenção da política linguística se dá em três eixos: oficial - vinculada às decisóes sobre a oficialidade das línguas; educacional - refere-se ao ensino das línguas; e o geral - ligado às línguas da comunicação, dos negócios e das relações entre estrangeiros. Spolsky (2004 apud SEVERO, 2013) apresenta a política linguística como uma vinculação entre as políticas e as práticas locais, mostrando que seus elementos formadores tais quais a gestão de línguas - política explícita e oficial para o uso das línguas; as crenças e ideologias linguísticas em relação com os usos linguísticos; e as práticas linguísticas que têm a ver com os padróes interacionais. Por um lado, dá-se ênfase às relaçóes de poder verticais, do Estado para a população, e, de outro lado, sobressaem as relaçóes horizontais entre os sujeitos que estão inscritos nessa língua pela história.

Diante das formas diferentes de delimitar planejamento linguístico, Coo- 
per (1997) recolheu doze definições de vários autores para, enfim, apresentar sua conclusão: "O planejamento linguístico (grifo nosso) compreende os esforços deliberados para influir no comportamento de outras pessoas a respeito da aquisição, da estrutura ou da correspondência funcional dos seus códigos linguísticos". De certo modo, sua definição estabeleceu os marcos descritivos para planejar uma língua tais como a função, a forma, a aquisição e a mudança social (COOPER, 1997, p. 10).

A primeira se refere às funções da língua: oficial; municipal- quando ela se torna oficial apenas em uma cidade e não no território nacional -; comunicação comunitária - embora não seja oficial, cumpre funçóes comunicativas essenciais entre comunidades de línguas diferentes -; internacional - exerce seu papel para relaçóes diplomáticas, turísticas e comerciais -; capital - se a comunicação, para exercer o poder político, o prestígio social e a atividade econômica, concentre-se na capital; grupal-símbolo de pertencimento a uma comunidade e meio básico de comunicação entre membros de um grupo cultural ou étnico -; educacional - língua como meio de instrução nos sistemas escolares em nível regional ou nacional -; disciplinar - como matéria no ensino médio e superior -; religiosa - uso linguístico para exortação, conversão e instrução religiosa - e literária.

A segunda inclui atividades linguísticas como a criação de novas palavras, mudanças na ortografia e a adoção de um novo sistema de escrita, isto é, seleciona estruturas que beneficiem determinada função a cumprir, tais quais mudanças na representação gráfica (criação e desenvolvimento de um sistema de escrita), a normalização (escolha de uma norma dentre os dialetos regionais e sociais) e a modernização (criação de vocabulário para as necessidades originárias das sociedades modernas).

No caso do planejamento pela aquisição de língua, as ações estão voltadas para promover a aprendizagem de uma língua, seja por revitalização ou manutenção, seja como segunda língua (L2) ou língua estrangeira (LE), podendo ser, muitas vezes, estimulada e ensinada nas escolas.

Em relação à mudança social, alguns fatores colaboram para a mesma: o meio físico, a população, o descobrimento e a invenção, a difusão cultural, a ideologia e a adoção de decisóes. De qualquer forma, todo planejamento linguístico não se passa fora do contexto social nem da história que o origina. Ainda que atenda, frequentemente, aos interesses das elites, também servem 
às massas para fins de identidade, dignidade, autoestima, pertencimento a um grupo e integração social.

Antes de estabelecer os marcos descritivos de uma língua, Cooper (1997) utiliza-se de alguns critérios para avaliação de políticas linguísticas, ponderando não só "o que" planeja, "quem" e "para quem" planeja, mas também "por que", "como", "onde" e "quando". Esses critérios serão detalhados mais adiante, levando em consideração a valorização das línguas minoritária e majoritária para o ensino de surdos da educação básica.

Há mais uma vertente, usada por Haugen (1971) e defendida por Guespin e Marcellesi (1986), a de nomear Glotopolitica todas as formas de ação social sobre a linguagem, podendo ser fruto da luta social, de estudos acadêmicos ou de órgãos do Estado, a fim de designar uma análise ou sem ao menos saber. No entanto, o pesquisador deve ter compromisso com o seu papel político, social e ideológico (ARNOUX apud LAGARES; SAVEDRA, 2013).

Diante de todo esse panorama, em primeiro lugar, devemos esclarecer sobre as políticas que asseguram os direitos linguísticos dos surdos. Em segundo lugar, elencamos os preceitos de Cooper (1997), Calvet (2002) e Severo (2013) para a avaliação de uma política linguística institucional no INES em comparação às políticas públicas direcionadas para essa minoria linguística na educação básica.

\section{Direitos Linguísticos e Avaliação de Políticas Linguísticas no Brasil}

Conforme apresentado anteriormente, as politicas linguisticas podem ocorrer por regulamentação e implantação de leis, decretos, pareceres, mas também pelo modo como a comunidade coloca em prática essas políticas, seja por movimentos da comunidade nas associações, federaçóes, seja no âmbito social e nas escolas. Segundo Loubier (2002), o termo politica linguistica não é sinônimo de legislação linguística. Pode ser um conjunto de medidas administrativas (leis, regulamentos e decretos), além de expressar o uso das línguas em um território, de modo que, sendo uma e/ou outra, cumpram-se os direitos e obrigaçóes linguísticas.

O direito linguístico, segundo a autora supracitada (2002), tem por objeto o sistema linguístico ou a própria língua, sobretudo, para fixar regras de cer- 
to domínio social e, principalmente, garantir a proteção às minorias linguísticas. Assim, o direito linguístico sanciona, por meio de leis e outros dispositivos legais, os direitos linguísticos das pessoas e dos seus respectivos grupos sociais. No entanto, necessitamos considerar a partir de que momento é preciso intervir, por meios jurídicos, para estabelecer uma relação de forças entre dois ou mais grupos linguísticos; como uma lei pode distinguir os direitos individuais dos coletivos e quais são os limites dos domínios de intervenção possíveis?

A fim de buscar a resolução desses impasses, criaram-se os princípios da territorialidade e da personalidade. O primeiro apoia que uma língua predominante no seu território tenha assegurada sua sobrevida. É necessário que a comunidade linguística não seja dispersa, mais sim concentrada em uma dada região. Ao adotar esse princípio, deve-se evitar os efeitos discriminatórios, estabelecendo uma política linguística que não só tome medidas eficazes de proteção linguística para grupos majoritários, mas também que implemente mecanismos de acomodação de grupos minoritários. Assim sendo, as instituições políticas têm a obrigação moral de facilitar a assimilação linguística dos imigrantes, por exemplo.

O segundo princípio, por sua vez, relaciona-se ao direito do indivíduo em usar a sua língua materna (primeira língua) ou a língua oficial, se o país for bilíngue ou plurilíngue, ou seja, o Estado sustenta os direitos linguísticos individuais das minorias. Esse princípio da personalidade é altamente criticado, pois o Estado tende a valorizar mais as minorias que apresentam influências fortes na vida política, social e econômica da nação (LOUBIER, 2002). Apesar disso, diante dos dois princípios, a Libras estaria mais adequada ao da personalidade, porque os surdos não estão presos a um território único, além disso cada um tem o direito de usar sua primeira língua para expressar-se em todos os ambientes sociais, principalmente, na escola.

Nesse conceito de direito linguístico, ressaltamos a importância da Declaração Universal dos Direitos Linguísticos (DUDL) de 1996, pois permite "corrigir os desequilíbrios linguísticos com vista a assegurar o respeito e o pleno desenvolvimento de todas as línguas e estabelecer os princípios de uma paz linguística planetária justa e equitativa, como fator fundamental da convivência social". Esse dispositivo legal define os direitos linguísticos como simultaneamente individuais e coletivos, defende os direitos das pessoas pertencentes a minorias nacionais ou étnicas, religiosas e linguísticas, mas também declara 
que são inaceitáveis atos de discriminação contra as comunidades linguísticas com base em critérios econômicos, políticos ou sociais ou linguísticos por modernização ou normalização.

No início do documento, foram esclarecidos alguns conceitos como comunidade linguística e território. No artigo $1^{\circ}$, definem-se comunidade linguística como:

toda a sociedade humana que, radicada historicamente num determinado espaço territorial, reconhecido ou não, se identifica como povo e desenvolveu uma língua comum como meio de comunicação natural e de coesão cultural entre os seus membros. A denominação língua própria de um território refere-se ao idioma da comunidade historicamente estabelecida neste espaço (UNESCO, 1996, p. 4).

Entendemos o termo povo como "conjunto de pessoas que falam a mesma língua, têm costumes e interesses semelhantes, história e tradiçóes comuns [...] Conjunto de pessoas que vivem um uma comunidade num determinado território; nação; sociedade" (HOUAISS, 2009), portanto os surdos brasileiros vivem na sociedade brasileira, desenvolveram uma língua, a Libras, como meio de comunicação natural do surdo e conexão cultural, além de ser instaurada pela história. Entendemos também que os surdos se encontram no seu próprio território e pertencem a uma mesma comunidade linguística, porque as coletividades estão "estabelecidas num espaço geográfico que partilham com os membros de outras comunidades linguísticas com antecedentes históricos semelhantes". Nesse caso, os membros de outras comunidades linguísticas seriam os ouvintes, usuários de língua portuguesa e de outras línguas orais, viventes de acontecimentos históricos em comum em âmbito nacional.

Considerando que o enfoque desse artigo é avaliar a garantia, no ensino, dos direitos linguísticos de valorização de Libras e Português aos surdos da educação básica, realçamos, no DUDL, a seção II, com oito artigos, sobre o Ensino para as comunidades linguísticas minoritárias, incluindo como deve ser o ensino, que direitos elas têm em relação à sua língua e cultura e ao acesso de qualquer língua para comunicação com outras comunidades. Destacamos, por isso, os Artigos $24^{\circ}$ e $25^{\circ}$, já que ressaltam que as comunidades linguísticas têm 
direito a: decidir sobre como deve ser o grau de presença da sua língua em todos os níveis de ensino; dispor de todos os recursos humanos e materiais necessários para conseguir o grau de presença da sua língua em todos os níveis de ensino.

Em relação à política pública brasileira, o Decreto 5626 de 2005 regulamentador da Lei 10436 de 2002 que dispóe sobre a Libras, vem a confirmar, em parte, essa convenção internacional: "As instituiçôes federais de ensino devem garantir, obrigatoriamente, às pessoas surdas acesso à comunicação, à informação e à educação [...], nas atividades e nos conteúdos curriculares desenvolvidos em todos os níveis [...] de educação" (BRASIL, Decreto 5626/05, Art. $1^{\circ}$ ). Admoestamos que esse Decreto atende os direitos linguísticos parcialmente, porque dirige a responsabilidade de garantir às pessoas surdas o aprendizado, a comunicação e a informação em Libras (e também os recursos humanos e materiais) somente às instituiçôes federais, não cabendo a participação dos membros dessa comunidade linguística, conforme previsto na Declaração. Nesse sentido, pelos preceitos de Cooper (1997), o decreto falha nos critérios de quem e como se planeja essa política linguística para o surdo.

Ressaltamos ainda que, em 2014, foi convocado pelo Ministério da Educação (MEC) um grupo de trabalho, sobre a educação bilíngue para surdos, com a participação de membros dessa comunidade linguística, mais pesquisadores e acadêmicos da área, com o objetivo de propor mudanças no campo das políticas linguísticas para surdos no país, tais como uma educação bilíngue que vincule "uma educação linguístico/cultural e não a uma educação especial marcada pela definição da surdez como falta sensorial, como anomalia a ser reabilitada ou corrigida por tentativas cirúrgicas" (BRASIL, 2014, p. 6). Embora essa açáo seja um dos primeiros passos, por parte do Estado, de garantir a presença da comunidade linguística na decisão sobre o uso da sua língua no ensino, esse relatório não foi levado adiante para discussão e implementação na educação brasileira. Mais uma vez, segundo as determinaçóes de Cooper (1997), o Estado resolveria a falha nos critérios "quem" e "como", no entanto não quis assumir essa responsabilidade na aplicação da política.

As medidas supracitadas, tomadas pelo Estado, são consequências de uma política linguística brasileira que teve um longo período de "silenciamento e interdição das línguas em prol de um Estado Nacional alicerçado sobre a língua Portuguesa como única língua oficialmente reconhecida e promovida” (MORELLO, 2012, p. 32), porém, atualmente, há outros momentos 
de afirmação e promoção da diversidade linguística: a Libras como meio de expressão e comunicação em território nacional; a cooficialização de línguas por município, como o pomerano em algumas cidades do Espírito Santo; a realização de programas de educação escolar bilíngues e a oferta de cursos universitários visando à formação em línguas indígenas, de sinais e de imigrantes.

Além disso, cabe lembrar que existem mais de 200 línguas faladas no Brasil entre indígenas, de imigração, de sinais, crioulas e afro-brasileiras, além do português e de suas variedades. Esse patrimônio cultural, muitas vezes, não se reconhece, porque a crença de que o Brasil é um país monolíngue permanece. Muitos grupos de civis e do governo tomaram a iniciativa de tentar mudar essa conjuntura e também conseguiram implementar o Decreto no 7.387, de 9 de dezembro de 2010, que instituiu o Inventário Nacional de Diversidade Linguística (INDL) como "instrumento de identificação, documentação, reconhecimento e valorização das línguas portadoras de referência à identidade, à ação e à memória dos diferentes grupos formadores da sociedade brasileira” (BRASIL, 2010).

Esse inventário fundado, por meio de decreto assinado pelos ministérios da Cultura (MinC), da Educação (MEC), da Justiça (MJ), da Ciência e da Tecnologia (MCTI) e do Planejamento, Orçamento e Gestão (MP), autoriza que as línguas sejam inventariadas, desde que tenham relevância para a memória, a história e a identidade dos grupos que fazem parte da sociedade brasileira. Depois disso, as línguas incluídas no INDL receberão título de "Referência Cultural Brasileira”, possibilitando, desse modo, valorização e promoção de políticas públicas por parte do poder público.

É essencial sinalizar que essa ação deve contar com a contribuição de comissão técnica, órgãos, instituições desde a esfera municipal à federal, além de entidades da sociedade civil e de representaçóes de usuários das línguas. Destacamos que esse decreto se tornou realidade, devido à luta incansável de algumas entidades civis e governamentais, e contribui muito para o reconhecimento, fortalecimento e motivação das línguas minoritárias por parte do governo, através de políticas públicas, e da população.

Oliveira (2015, p. 26) afirma que "os direitos linguísticos no Brasil, pela legislação existente, foram alocados dentro dos direitos educacionais, embora na realidade, [...] sejam demandados em todas as situaçóes de vida dos cidadãos, e não apenas no âmbito escolar”, ou seja, observamos que as políticas linguísticas, no Brasil, são em grande parte operadas no interior das políticas 
educacionais. Dessa forma, busca-se analisar como são garantidos os direitos linguísticos dos surdos à valorização da Libras e do Português no Plano de Desenvolvimento Institucional do INES (PDI-INES).

Esse documento está em vigor desde 2012 até o ano de 2016, no que se refere à educação básica, por alguns motivos. Em primeiro lugar, o INES é uma instituição que tem o seu colégio de aplicação $\left(\mathrm{CAp} / \mathrm{INES}^{2}\right)$, assegurado pelo decreto no 7.690, de 2012, capítulo III, seção II, artigo 35, que dispóe como uma das competências do instituto "promover a educação de alunos surdos, através da manutenção de órgão de educação básica, visando a garantir o atendimento educacional e a preparação para o trabalho de pessoas surdas". Compreende-se, portanto, que essa é uma escola singular, já que só atende alunos surdos. Em segundo lugar, cabe observar como a instituição está construindo, atualmente, a trajetória educacional dos seus alunos, por meio do que se escreve no documento.

Considerando os critérios de Cooper (1997) para esse dispositivo legal, elencamos as seguintes informações no planejamento da política linguística:

$\checkmark$ Quem planeja: o INES

$\checkmark$ O que: estimular a inclusão social e a cidadania das pessoas surdas nas políticas educacionais do Brasil em uma perspectiva bilíngue - Libras e Português;

$\checkmark$ Para quem: Para as pessoas surdas a serem atendidas pelas políticas educacionais brasileiras, seus familiares e colegas da escola e do trabalho, bem como por profissionais que atendam essas pessoas.

$\checkmark$ Por quê: É um plano estratégico desenvolvido pela instituição de Educaçáo Superior (DESU), porque realiza seu compromisso social, de acordo com a Lei no 5.773 , de $2006^{3}$.

2 O Colégio de Aplicação do Instituto Nacional de Educação de Surdos (CAp/INES), sob responsabilidade do Departamento de Educação Básica do instituto (DESASI), oferece atendimento a crianças, adolescentes e adultos surdos, nos seguintes segmentos da educação básica: educação infantil e ensinos fundamental e médio. O CAp/INES possui também o Centro Atendimento Alternativo Florescer (CAAF) e o Núcleo de Estudos Avançados - Pré-Vestibular. Disponível em: <http://portalines.ines.gov.br/ines_portal_novo/?page_ $\mathrm{id}=262>$. Acesso em: 03 jun. 2014.

3 Esse Lei dispóe sobre o exercício das funções de regulação, supervisão e avaliação de instituições de educação superior e cursos superiores de graduação e sequenciais no sistema federal 
$\checkmark$ Como: Por meio de objetivos e metas para as Políticas Públicas e Relações Institucionais; Educação Superior; Educação Básica; Saúde, Surdez e Educação; Gestão do Conhecimento e Gestão Institucional.

$\checkmark$ Onde: Na Missão Institucional do INES.

Quando: No período de 2012 a 2016.

Enfocamos a análise do documento nas Políticas Públicas e Relações Institucionais e na Educação Básica. No caso do $1^{\circ}$ objetivo, ressaltamos a participação na formulação e execução das políticas nacionais de educação, na perspectiva bilíngue (Libras e Português), que tem como meta entrar na discussão e implementação do Plano Nacional de Educação (PNE); a promoção e apoio de políticas linguísticas que contribuam para a valorização e difusão da Libras como patrimônio imaterial do País e favoreçam a sua aquisição por membros da comunidade linguística, seus familiares ouvintes, colegas de escola e trabalho, bem como por profissionais que atendam essas pessoas. Tudo isso a fim de participar da comissão técnica responsável pelo INDL, além de metas institucionais, como criação de cursos de Libras à distância, maior oferta nos cursos presenciais e realizar o Exame Nacional de Certificação de Proficiência em Libras - Pró-LIBRAS.

Em relação à Educação Básica, há um grande objetivo com muitas metas a serem realizadas: promover a educação dos alunos surdos, pelo órgão da Educação Básica, com o intuito de garantir a escolarização - educação infantil, fundamental, média e de jovens e adultos - a educação profissional e a passagem para o trabalho de pessoas surdas. Quanto às metas desse objetivo, damos destaque ao Edital de Concurso Público para o magistério da Educação Básica com valorizaçáo da experiência de trabalho com surdos e do conhecimento de Libras; promover reunióes conjuntas entre a equipe de Libras e a equipe de Língua Portuguesa, com o desejo de aperfeiçoar a proposta de educação bilíngue e efetivar a Libras, como L1, e o Português, como L2, para leitura e escrita e ampliar a oferta de curso de Libras aos familiares dos alunos do CAp/INES.

Observamos, desses objetivos e metas citados anteriormente, que há teoricamente um reconhecimento, uma promoção e um fortalecimento dos direitos linguísticos dos surdos de valorização da Libras (L1) e da Língua Por-

de ensino (BRASIL, Lei 5.773/06). 
tuguesa (L2) na Educação Básica, no que diz respeito ao ensino no INES, à associação com algumas políticas públicas do país como o Decreto 5626/05, INDL, PNE e à conformidade com a Declaração Universal de Direitos Linguísticos sobre o pleno desenvolvimento das línguas que podem colaborar para a convivência social pacífica. Cabe, no entanto, estar atento às práticas escolares e sociais que efetivam essas ações ditadas nas políticas linguísticas (COOPER, 1989 apud SEVERO, 2013).

\section{Considerações Finais}

Percebemos que, embora o Brasil tenha tido um longo período de silenciamento das mais de 200 línguas faladas no Brasil entre indígenas, de imigração, de sinais, crioulas e afro-brasileiras, além do português e de suas variedades, há algumas políticas nacionais de fortalecimento e promoção da diversidade linguística. Dentre elas, destacamos que o INDL se tornou um instrumento de reconhecimento das línguas minoritárias brasileiras, reforçando uma orientação da Declaração Universal dos Direitos Linguísticos.

Por fim, considerando o objetivo deste artigo, evidenciamos as políticas educacionais que respeitam, em parte, os direitos linguísticos dos surdos à valorizaçâo da Libras e da Língua Portuguesa: a Lei no 10436 de 24 de abril de 2002 - Institui a Libras como meio de expressão e comunicação no território brasileiro, mas não pode substituir a modalidade escrita da Língua Portuguesa; o Decreto no 5626 de 22 de dezembro de 2005 - estimula o ensino da Libras, com recursos materiais e humanos, em todos os níveis da educação, mas sem a participação dos membros da comunidade linguística; o PDI-INES - depois de avaliado sob os critérios de Cooper (1997) - reconhece, promove e fortalece os direitos linguísticos dos surdos, mas sempre cabe um olhar atento às práticas escolares e sociais que efetivam as ações ditadas nas políticas linguísticas.

\section{Referências}

. Decreto no 5626 de 22 de dezembro de 2005. Regulamenta a Lei $n^{o}$ 10.436, de 24 de abril de 2002, que dispóe sobre a Lingua Brasileira de Sinais - Libras, e o art. 18 da Lei ${ }^{\circ} 10.098$, de 19 de dezembro de 2000. Brasília: Presidência da República, Casa Civil, Subchefia para Assuntos Jurídicos. Disponível em: <http://www.presidencia.gov.br/ccivil/ _Ato2004-2006/2005/ Decreto/D5626.htm>. Acesso em: 18 ago. 2015. 
. Decreto no 7.690, de 2 de março de 2012. Aprova a Estrutura Regimental e o Quadro Demonstrativo dos Cargos em Comissáo e das Funçóes Gratificadas do Ministério da Educação. Disponível em: <http://www.planalto. gov.br/ccivil_03/_Ato2011-2014/2012/Decreto/D7690.htm>. Acesso em 28 nov. 2015.

Decreto no 7.387, de 9 de dezembro de 2010. Institui o Inventário Nacional da Diversidade Linguistica e dá outras providências. Disponível em: <http://www.planalto.gov.br/ccivil_03/_Ato2007-2010/2010/Decreto/ D7387.htm>. Acesso em: 13 mai. 2016.

. Lei ${ }^{\circ} 10.436$, de 24 de abril de 2002. Dispóe sobre a Lingua Brasileira de Sinais - Libras e dá outras providências. Disponível em: <http://www.planalto.gov.br/CCIVIL/LEIS/2002/L10436.htm>. Acesso em: 18 ago. 2015.

. Plano de Desenvolvimento Institucional do Instituto Nacional de Educação de Surdos (PDI-INES). Disponível em: <http://www.ines.gov.br/uploads/institucional/PDI-2012-2016.pdf>. Acesso em: 08 mar. 2013.

BRASIL/MEC/SECADI. Relatório do Grupo de Trabalho designado pelas Portarias $n^{\circ}$ 1.060/2013 e $n^{\circ}$ 91/2013. Subsídios para a Política Linguística de Educação Bilíngue - Língua Brasileira de Sinais e Língua Portuguesa - a ser implementada no Brasil, 2014b. SBU: Sistema de Bibliotecas da Unicamp. Disponível em: http://www.bibliotecadigital.unicamp.br/ document/?code=56513 - Acesso em 6 mar. 2016 .

CALVET, Louis-Jean. As politicas linguísticas. São Paulo: Parábola Editorial: IPOL, 2007.

COOPER, Robert L. La planificación linguística y el cambio social. $1^{\mathrm{a}}$ ed. Cambridge, United Kingdom: Cambridge University Press, 1997.

GUESPIN L.; MARCELLESI J.-B. Pour la Glottopolitique. Langages, n. 83, 1986, p. 5-34. Tradução: Marcos Bagno, julho de 2016.

HOUAISS, Antônio; VILLAR, M. S. Dicionário Houaiss da lingua portuguesa. 1. Ed. Rio de Janeiro: Objetiva, 2009.

LOUBIER, Christiane. Le droit linguistique et les droits linguistiques. Banq: Bibliotèque et Arquives Nationales Du Quèbec. Montréal: Office de la langue française, 2002. Disponível em: <http://collections.banq.qc.ca/ark:/52327/ bs48264>. Acesso em: 14 mai. 2016.

MORELLO, Rosângela. Uma política pública e participativa para as línguas brasileiras: sobre a regulamentação e a implementaçáo do Inventário Nacional da Diversidade Linguística (INDL). Revista Gragoatá (UFF), n. 32, p. 31-41, 2012 
OLIVEIRA, Gilván Muller A cooficialização de línguas em nível municipal no Brasil: direitos linguísticos, inclusão e cidadania. In: Leis e Linguas no Brasil. O processo de cooficialização e suas potencialidades. MORELLO, R. (org.) Florianópolis: IPOL, 2015.

ORLANDI, E. L. P.; Ser diferente é ser diferente: a quem interessam as minorias? In: Linguagem, Sociedade, Politicas, 10/2014, ed. 1, 9788561622534, RG, pp. 10, pp.29-38, 2014.

SAVEDRA Mônica Maria Guimarães; LAGARES, Xoán Carlos Diez. Política e planificação linguística: conceitos, terminologias e intervenções no Brasil. Revista Gragoatá (UFF), v. 32, p. 12-35, 2012.

SEVERO, Cristine Görski. Políticas linguísticas e questôes de poder. In: Alfa. São Paulo, n. 57, p. 451-473, 2013. < http://seer.fclar.unesp.br/alfa/article/ viewFile/5132/4670> Acesso em 05 jan 2016.

UNESCO. Declaração Universal dos Direitos Linguísticos. DHNET. Barcelona, jun. 1996. Disponível em: <http://www.dhnet.org.br/direitos/deconu/a_pdf/ dec_universal_direitos_linguisticos.pdf>. Acesso em 03 mar. 2016.

\title{
THE LINGUISTIC RIGHTS IN THE EDUCATION OF DEAF PEOPLE IN BRAZIL: A RECOGNITION OF LANGUAGES?
}

\begin{abstract}
This paper is about the education of deaf people in Brazil, concerning their linguistic rights of recognition of the Brazilian sign language (LIBRAS) and the Portuguese Language in the National Institute of Deaf Education (INES). This study compares the Institucional Development Plan with the Universal Declaration of Linguistic Rights (1996) and the main Brazilian public policies which concern this minority community.
\end{abstract}

KEYWORDS: Linguistic rights; deaf; language.

Recebido em: 31/05/2016 Aprovado em: 18/10/2016 